\title{
вмJ Global Health Forest malaria: the prevailing obstacle for malaria control and elimination in India
}

\author{
Raju Ranjha, ${ }^{1}$ Amit Sharma ${ }^{2,3}$
}

To cite: Ranjha R, Sharma A. Forest malaria: the prevailing obstacle for malaria control and elimination in India. BMJ Global Health 2021;6:e005391. doi:10.1136/ bmjgh-2021-005391

Handling editor Seye Abimbola

- Additional online supplemental material is published online only. To view, please visit the journal online (http://dx.doi.org/10.1136/ bmjgh-2021-005391).

Received 15 February 2021 Revised 13 April 2021 Accepted 27 April 2021

\section{Check for updates}

(c) Author(s) (or their employer(s)) 2021. Re-use permitted under CC BY-NC. No commercial re-use. See rights and permissions. Published by BMJ

'ICMR-National Institute of Malaria Research, Raipur, Chhattisgarh, India

${ }^{2}$ ICMR-National Institute of Malaria Research, New Delhi, Delhi, India

${ }^{3}$ Molecular Medicine, International Centre for Genetic Engineering and Biotechnology, New Delhi, India

Correspondence to

Dr Raju Ranjha;

dr.ranjha01@gmail.com

\section{ABSTRACT}

Despite the decrease in malaria mortality and morbidity, it remains a significant public health problem in India India is targeting malaria elimination from the country by 2030. Different areas in India are in different phases of malaria elimination. The emerging resistance in vectors as well parasite have added necessity to accelerate the malaria elimination programme. Forested areas remain the foci for malaria transmission due to favourable human and environmental factors. Here, we analysed the longitudinal data from 2000 to 2019 to see the trends in forest malaria in India. Population living in forested areas are major malaria contributors. From 2000 to 2019, 32\% of malaria cases and $42 \%$ of malaria related deaths were reported from forested districts which represent only $\sim 6.6 \%$ of the total Indian population. Increasing insecticide resistance, a high percentage of submicroscopic infections and challenging to test and treat communities are the crucial components of the prevailing obstacles of forested malaria. To achieve the elimination goal, efforts should be intensified with more resources diverted to the forested areas. Malaria control in forested areas will bring fruitful results for malaria control in India.

\section{INTRODUCTION}

India with an estimated 5.6million (2.4\%) cases and 7705 (1.9\%) deaths of the world's total was among the top 32 malaria endemic countries. A continuous decrease in malaria has been reported from India with the largest absolute reductions in the WHO South-East Asia Region, from about 20 million cases in 2000 to about 5.6 million in $2019 .{ }^{1}$ India launched the National framework for malaria elimination with a target to eliminate malaria from the country by 2030. India is the only country in the high malaria burden countries which has a high domestic investment for malaria programme compared with the international investment showing its commitment towards the cause. ${ }^{1}$ However, despite significant progress in malaria control by India, it is still a public health problem in several parts of the country with $95 \%$ of the Indian population living in malaria-endemic areas. ${ }^{2}$
Summary box

National malaria elimination programme in India has targeted malaria elimination by 2030 .

- $6.6 \%$ of the total Indian population which lives in forested areas of India contributed $\sim 21 \%$ cases and $\sim 53 \%$ of deaths in 2019 .

- The primary malaria vector in central India with forested regions are increasingly resistant to insecticides.

- A high percentage of asymptomatic and submicroscopic malaria indicates hidden parasite reservoirs in these regions.

- Malaria control with increased community participation and new vector control tools are needed in the forested areas.

There are several challenges to this ambitious goal that are needed to be addressed. Forest malaria is one such big roadblock. The recent declines in malaria are due to new malaria policies that is, Artemisinin Combination Therapy (ACT), use of rapid diagnostics and long lasting insecticide nets (LLIN). However, the reduction that has been observed in malaria cases and deaths in India is heterogeneous. Indeed, elimination can be facilitated by targeting all malaria foci with malaria transmission. ${ }^{3}$

Malaria is a focal disease whose epidemiology is affected by human, vector, parasite and environment. The latter in India is diverse and includes plains, hills, coasts and desert areas. The different environmental conditions with multiplicity of vectors for transmission present a complex malaria control challenge. In addition, insecticide and drug resistance, poor adherence to drugs, inadequate surveillance and inaccessible swathes of land makes India's fight against malaria tough to sustain. ${ }^{4-6}$ To eliminate malaria, it is needed to be seen in smaller units to implement effective measures. It requires understanding and targeting interventions among high-risk groups. Malaria can be divided into 
different ecotypes including, forest and forest fringe, savanna, plains and valleys, foothill, mountain fringe and northern and southern fringes; desert fringe; coastal and urban. ${ }^{78}$ Clusters of malaria cases are closely associated with dense forest cover in Southeast Asia. Forest ecosystems provide favourable conditions for the vectors and are known for the presence of highly efficient malaria vectors. ${ }^{9}$ Communities living in forests are also the most challenging to test, treat and follow-up. ${ }^{10}$ Due to the ambient conditions for transmission and difficulties in control efforts in the forest ecosystems, it is of immense importance to focus on these areas for the ongoing control efforts. Despite being malaria hotspots, no analysis has been attempted so far on delineating the different malaria scenario in forested areas, and the strategic relevance of focusing on these malarious hotspots in India. Here, we provide longitudinal analysis of malaria epidemiological data from India in context of forested regions within the country. For this study, epidemiological data from National Vector Borne Disases Control Programme
(NVBDCP) for the year 2000-2019 (except 2006 where data were not available) have been analysed to assess forest malaria longitudinally. We have selected districts with forest cover of $40 \%$ and above (figure land online supplemental table 1). The rest of the districts will be addressed as others/non-forested from hereon.

\section{FORESTS AND MALARIA TRANSMISSION}

Forest cover is calculated based on tree canopy density. It is divided into very dense forest $(\geq 70 \%)$, moderately dense $(40 \%-69 \%)$, open forest $(10 \%-39 \%)$, scrubs $(<10 \%)$ and non-forest (areas not included in other class). ${ }^{11}$ Up to $\sim 21 \%$ of India's geographical area is covered by forests. The first two categories that is, very dense and moderately dense are included in the analysis for forest malaria. The forested areas of these densities would be ecologically more receptive to malaria as compared with areas with lesser canopy densities. Also, these categories present a more challenging situation to the healthcare

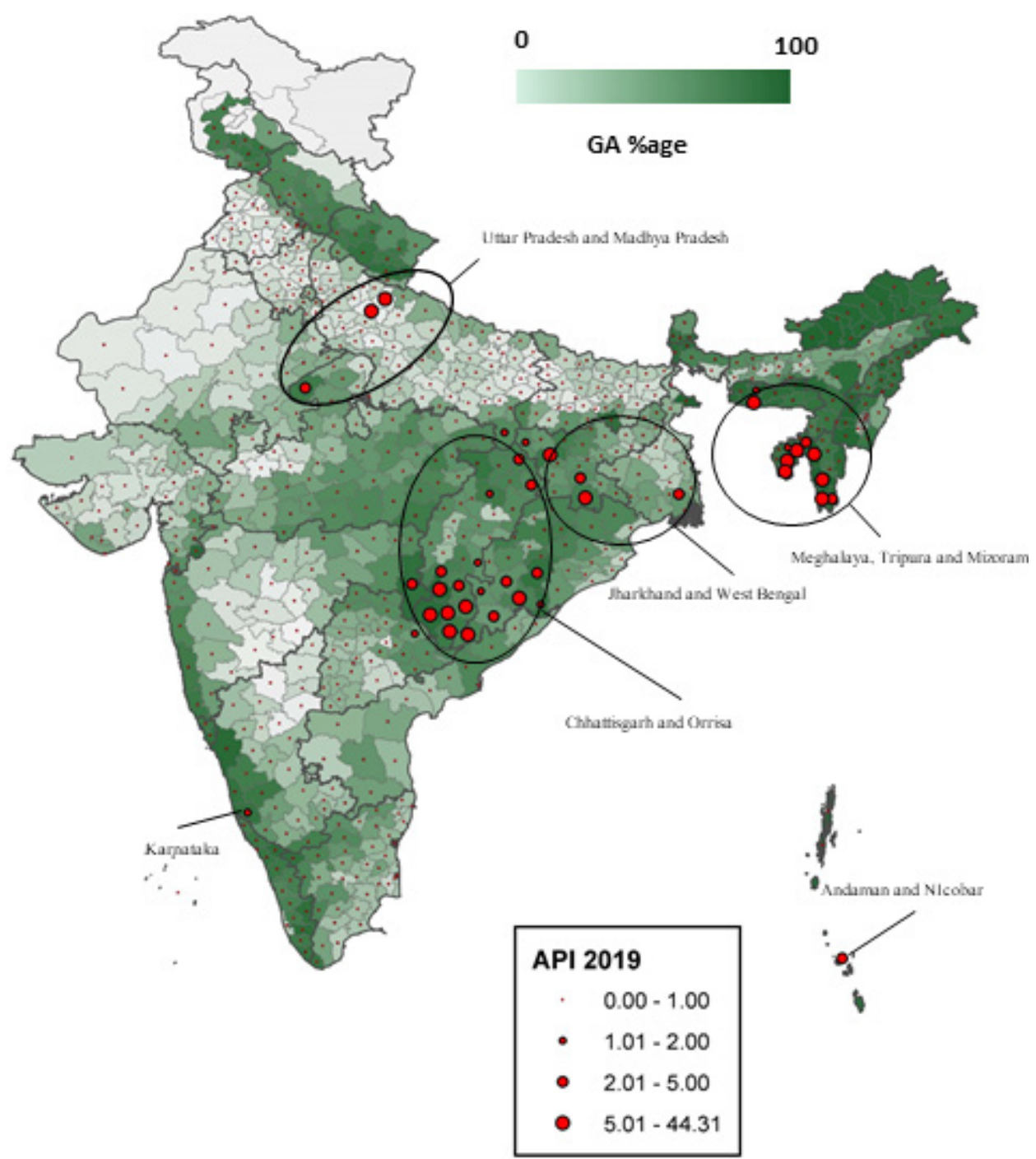

Figure 1 Percentage of geographical area (GA) covered and malaria endemicity in India. Big red dots lying in the greener areas indicate high malaria endemicity and lie in the areas with very dense forest canopy. States where the high malarious districts map are highlighted. API, Annual Parasite Index. 

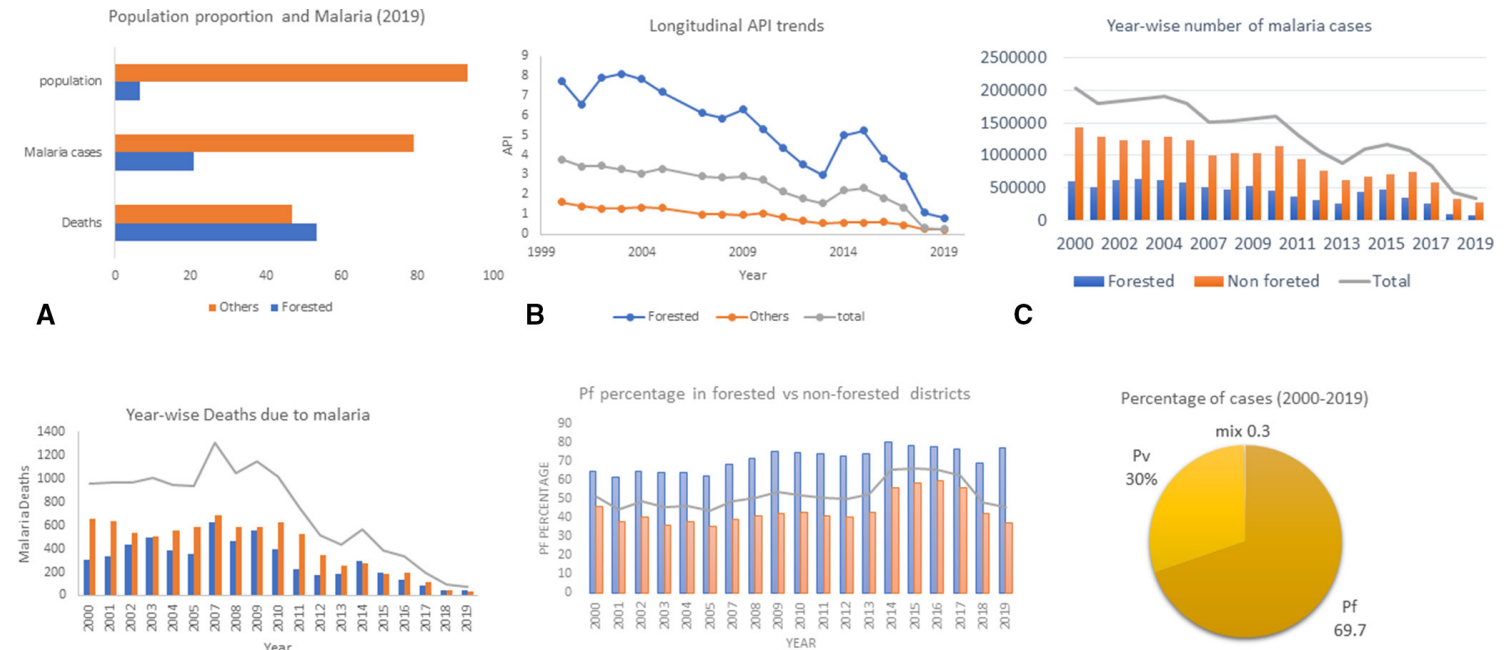

D

E

$\square$ Forested $\square$ ochers —india

$\mathbf{F} \quad \| p f=p v=$ mix

Figure 2 Malaria trends in forested and non-forested Indian districts. (A) Population proportion represents the percentage living in forested areas and other areas for the year 2019. Malaria cases and deaths are represented as percentage of total for the period 2000-2019. (B) Year-wise API trends in forested versus other areas from 2000 to 2019. (C) Year-wise malaria infections in forested vs other areas from 2000 to 2019. (D) Year-wise malaria mortality from 2000 to 2019. (E) Longitudinal trends in Pf percentage from 2000 to 2019. (F) Proportion of total infection due to $P v / P f / P v+p f$ (mix) in the forested areas from 2000 to 2019. API, Annual Parasite Index

system in their mitigation efforts in terms of accessibility and provision of services thus limiting their outreach. Hence, these two would be considered 'forested' areas in true sense.

Clusters of malaria cases are closely associated with dense forest cover regions within India (figure 1). Forest and forest fringe regions are reported to be associated with high malaria burden and deaths. ${ }^{12}$ The presence of favourable factors like temperature buffering, humidity, high organic content in breeding sites and the presence of streams make forest ecosystems suitable for malaria vector breeding leading to high transmission. ${ }^{13-15}$ In India, usually tribal people inhabit the forested areas. Their cultural belief systems, poverty, lack of infrastructure and communication make these areas vulnerable to malaria morbidity and mortality. The Indian districts with moderate and high forest covers are inhabited by $\sim 6.6 \%$ of the total Indian population. Nevertheless, the malaria cases reported from these districts are $\sim 21 \%$ of the total reported cases,in 2019 in India (figure 2A). Indeed of the total malaria cases (25 689 287) reported in the country from 2000 to $2019, \sim 31.9 \%$ were from the forested districts. A total of 13682 people died due to malaria from 2000 to 2019 of which $42 \%$ were reported from the forested districts. Hence, these data reveal that both morbidity and mortality due to malaria are high per population proportion in the forested districts.

\section{MALARIA BURDEN IN FORESTED DISTRICTS VIS-À-VIS REST OF INDIA}

Historically, the forested areas had been malaria hot spots due to conducive environments. The Annual Parasite Index (API) in the forested districts has continuously been high compared with the non-forested districts-it was four times the API of non-forested districts in the 2000. For the year 2019, the API is still in the ratio of 3:1 (forested: non-forested). Highly favourable climatic conditions including high humidity and ambient temperature in the forested areas may be the reason for high malaria cases in the areas. In addition, the lack of treatment seeking behaviour of the community may contribute towards high death rate as residents tend to prefer unlicenced medical practitioners (UMPs), selfmedication and superstitious remedies over govt doctors or healthcare staff. ${ }^{16}{ }^{17}$ Poor economic conditions of the inhabitants also contributes to increased malaria vulnerability. ${ }^{18} 19$ Forest areas are hard to reach and inaccessibility is exaggerated by rains, difficult terrains and sparsely populated locales. The communities inhabiting these are often resistant to medical advice. ${ }^{10}$, Thus despite the considerable decline in India's malaria prevalence, the forested areas are still the major contributors to the total malaria cases despite their low population (figure 2B,C). The significant decrease in malaria in India in the past $\sim 5$ years is contrasted by lower declines in forested districts (figure 2B).

As shown in figure 2, malaria control in $\sim 6.6 \%$ of the forested Indian population show visible impacts on malaria data of the whole country. Therefore, malaria control efforts directed at these areas will push India faster towards malaria elimination. Some of forested districts retain very high malaria endemicity (table 1 ). Although, from 2000 to 2019 annual malaria mortality in India decreased significantly (figure 2D), the decline in forested districts is $\sim 2.5$-fold less compared with other areas of the country (figure 2). The proportion of deaths from forested districts has actually increased from $32 \%$ in year 2000 to $53.2 \%$ in 2019 (figure 2D). Hence, although 


\begin{tabular}{lllll}
\hline Table 1 & Indian forested districts with & API $\geq 2$ in 2019 & & \\
\hline Sr. no & State & District & API & GA covered by forest (\%) \\
\hline 1 & Chhattisgarh & Bastar (Kondagaon,Bijapur) & 7.14 & 53.50 \\
2 & Chhattisgarh & Dantewada (Sukma, Narayanpur) & 27.90 & 64.24 \\
3 & Chhattisgarh & Kanker & 3.25 & 47.56 \\
\hline 4 & Madhya Pradesh & Sheopur & 4.32 & 53.30 \\
\hline 5 & Maharashtra & Gadchiroli & 2.10 & 70.04 \\
\hline 6 & Meghalaya & South Garo Hills & 7.95 & 88.64 \\
\hline 7 & Mizoram & Lunglei & 15.00 & 92.72 \\
\hline 8 & Mizoram & Saiha & 4.23 & 92.21 \\
\hline 9 & Mizoram & Mamit & 21.14 & 91.70 \\
\hline 10 & Mizoram & Lawngtlai & 25.89 & 92.61 \\
\hline 11 & Odisha & Phulbani (Kandhamal) & 3.53 & 68.18 \\
12 & Odisha & Rayagada & 5.25 & 44.05 \\
13 & Tripura & Gomati & 5.82 & 66.49 \\
14 & Tripura & North Tripura & 2.82 & 74.25 \\
\hline 15 & Tripura & Dhalai Tripura & 7.56 & 79.60 \\
\hline 16 & Tripura & South Tripura & 8.25 & 80.90 \\
\hline 17 & Andaman and Nicobar & Nicobar & 4.89 & 75.01 \\
\hline
\end{tabular}

API, Annual Parasite Index; GA, geographical area.

there is significant malaria control in India but the pace of reduction in malaria mortality in quite low in the forested districts compared with other areas (figure 2B-D).

\section{PLASMODIUM DISTRIBUTION AND DRUG RESISTANCE}

The two major Plasmodium species responsible for malaria in India are Plasmodium falciparum (Pf) and Plasmodium vivax $(\mathrm{Pv})$. Both species are unevenly distributed in India. ${ }^{6}$ Out of total malaria cases in India 2000-2019, 52.4\% and $47.6 \%$ were due to $P f$ and $P v$. But the percentage of infection due to $P f$ for the period 2000-2019 were about $69.7 \%$ in the forested districts (figure 2F). Percentage of malaria cases in forested districts by $P f$ was about $50 \%$ of total malaria infections from 2000 to 2005 . From 2007 onwards there has been a steady increase and it was $77.6 \%$ for the year 2019 (figure 2E). The increased $P f$ percentage is one of the reasons for high proportion malaria deaths in India from these the areas. Drug resistance is one of the biggest challenges that malaria elimination programme may face. Pf dominated forest malaria had already become resistant to chloroquine in most of India leading to a change in drug policy towards ACTs. Of $\sim 80$ districts enlisted by NVBDCP in the chloroquine-resistant area, $33(41.2 \%)$ were forested. Due to reports of treatment failure to $\mathrm{AS}+\mathrm{SP}$ in north-eastern parts of the country, it has been changed to AL. $P v$ is responsible for $\sim 30 \%$ of malaria cases in the these areas but it offers separate challenges as compared with $\mathrm{P} f$. Administration of radical cure by primaquine for 14 days suffers from adherence issue. Currenly in some states like Chhattisgarh, patients have are referred to auxiliary nurse midwife by village health worker (Accredited Social Health Activist/Mitanin) for primaquine treatment. More community awareness and delivery of primaquine by village healthcare workers with regular follow-ups will be required for successful control of $P v$ in these areas. Poor and sparse healthcare facilities and lack of proper infrastructure makes the delivery of health services to these regions an onerous task.

Regular drug-resistance monitoring studies with rational use of medicines by increased dependence on licenced practitioners may help in mitigating this situation. Genomic studies for tracking and early prediction of drug resistance development are needed for timely response in case of drug failures due to resistance. It has been suggested that training UMPs along national guidelines for malaria diagnosis and treatment may strengthen their ability and may enable them to contribute for achieving of India's malaria elimination goals. The National programme has established Drug Distribution Centres and Fever Treatment Depots in rural areas for providing easy access to anti-malarial drugs and this may help in decreasing the dependence on UMPs. NVBDCP is also involving NGOs for sensitising communities for malaria control. ${ }^{2}$ Active community participation can lead to improvement in healthcare-seeking behaviour.

\section{VECTORS AND INSECTICIDE SUSCEPTIBILITY STATUS}

Social practices and beliefs of communities living in the forested areas may lead to their increased vulnerability towards malaria morbidity and mortality. Staying overnight in the farms and plastering home walls with 
fresh cow dung/mud may lead to increased exposure to mosquitoes and render the sprayed Indore residual spray (IRS) ineffective. Open houses of the tribal populations allow easy entry of malaria vectors into the house. ${ }^{18} \mathrm{Up}$ to now 58 Anopheles species have been described in India of which six are the primary vector for malaria transmission. The vector species for malaria transmission in the forested areas of central and eastern India are Anopheles culicifacies, Anopheles fluviatilis and Anopheles minimus. Of these Anopheles baimaii and An. minimus are the primary vectors in the forested areas of northeast Indian states. ${ }^{20}$ An. culicifacies is night biter with largely endophilic nature while An. fluviatilis displays exophilic nature as studied in a whole night light trap collection in Madhya Pradesh. ${ }^{20-23}$ Anopheles culicifacie and An. fluviatilis both are indoor night biters. ${ }^{22}{ }^{24} \mathrm{An}$. minimus displays endophilic nature in northeast India while it shows exophilic resting in east-central India. It is a highly endophagic, anthropophliic and a night biter. ${ }^{25}$ An. baimaii also has a very high anthropophilic index and although it is predominantly an endophagic night biter, outdoor biting has also been observed. ${ }^{26}{ }^{27}$ Except for An. culicifacie all the other malaria vectors in the forested areas of India are anthropophilic. And all are reported to be predominantly endophagic and night biters and thus the use of LLIN is one of the best tools for malaria control in these areas.

Primary malaria vectors in the forested areas of central India, especially An. culicifacies is developing resistance to almost all insecticide categories (organochlorines, organophosphates and pyrethroids) being used for IRS and in LLIN. ${ }^{28}$ An. culicifacies is resistant to DDT, malathion and deltamethrin in $100 \%, 75 \%$ and $46.67 \%$ of the forested districts where insecticide status was analysed (figure 3A). An. culicifacies is the primary malaria vector in forested areas of Chhattisgarh. In 2002, there was confirmed resistance to DDT and malation and the status for deltamethrin was verification required. In 2012, confirmed resistance to deltamethrin was reported. ${ }^{28}$ An. fluviatilis, An. Dirus and An. minimus were susceptible to the insecticides in use except for resistance against DDT (An. fluviatilis - $40 \%$ of the forest areas studies, figure 3B). Despite the resistance develpment it is advised to continue using LLIN to control malaria as it provides partial protection against malaria transmission. ${ }^{29}$

Entomological surveillance studies and regular insecticide resistance monitoring are needed in the forested areas. Timely analysis and utilisation of these data in planning vector control operations is also pertinent. Novel vector control measures like attractive toxic sugar baits, insecticide impregnated hammocks, and personal protective measures need to be explored in such communities . Increased community awareness and engagement is required for ensuring high LLIN usage and IRS coverage.

\section{PARASITE RESERVOIRS IN FOREST POPULATIONS}

Asymptomatic and low-density infections may act as reservoirs for malaria transmission. Studies have suggested that $\sim 44 \%$ of infections were subpatent and $\sim 80 \%$ of sub-patent infections were asymptomatic in the forested tribal villages of Chhattisgarh in 2016. ${ }^{30}$ The prevalence of asymptomatic carriers was $\sim 6 \%$ in Chhattisgarh and $\sim 66 \%$ of the carriers were found to be school age children (6-14 years) in $2017 .{ }^{31}$ In Odisha, submicroscopic and asymptomatic infection were reported to be $30 \%$ and $79 \%$ of the total infections, respectively, in $2019 .{ }^{32}$

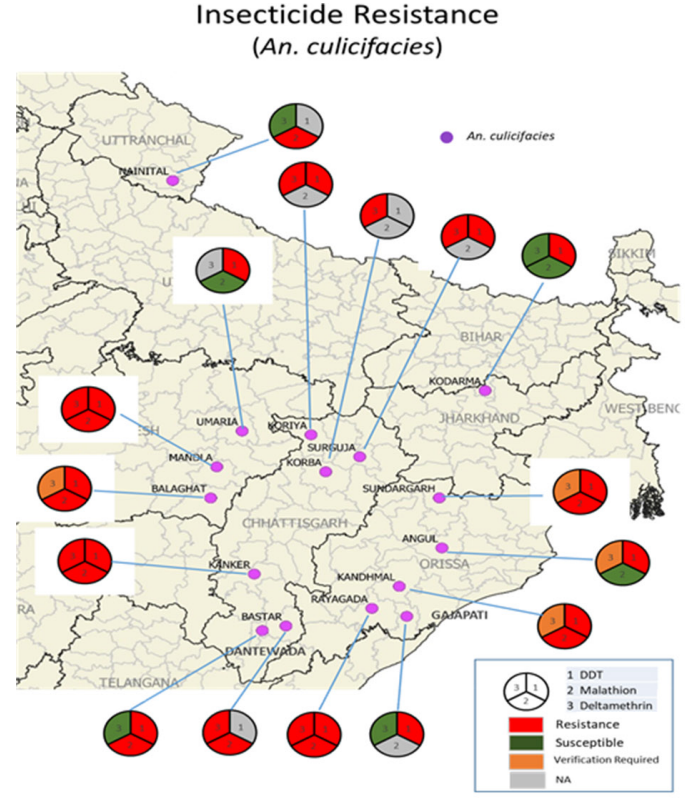

A
Insecticide Resistance (An. fluviatilis, An. dirus, An. minimus)

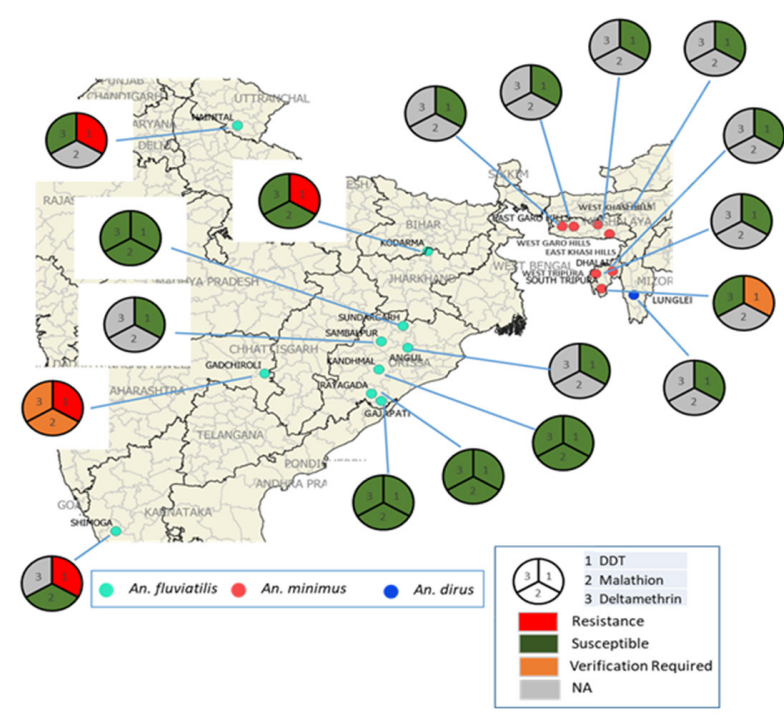

B

Figure 3 Insecticide resistance status of malaria vectors in forested areas of India. (A) Susceptibility status of Anopheles culicifacies. (B) Susceptibility status of Anopheles fluviatilis, Anopheles dirus and Anopheles minimus. 
Up to $8.4 \%$ of the tribal population in Bundwan block in the Purulia district, West Bengal was found to harbour Pf and all the infections were without any clinical manifestation. ${ }^{33}$ Genotyping cognate Plasmodium falciparum in human and mosquitoes revealed that asymptomatic infections have more than double the odds of transmission to a mosquito compared with asymptomatic infections. This study also suggested that in high transmission areas asymptomatic infections are the major contributors to mosquito infections. ${ }^{34}$ Although there are limited number of studies on asymptomatic and low-density infections from India, the available data show the presence of reservoir in the forested districts of central and eastern India.

Submicroscopic malaria cases pose as a threat to malaria and elimination control efforts. Studies have shown that subpatent infections contribute 20\%-50\% of human to mosquito transmission, ${ }^{35}$ indicating its potential in continued transmission of malaria in the communities. Inability of routine diagnostics like RDTs and microscopy to detect these due to low density parasitaemia further exaggerates the problem. Molecular tools like PCR are resource intensive and are not point-of-care tests, rendering diagnosis of subpatent malaria at grassroot level, more so in these underserved forested areas, an inexecutable task. There is an urgent need to develop and test simple-to-use field-friendly PCR tools which can be used at least at the level of primary healthcare, if not lower. These would augment the diagnostic capacities of the health systems for the sub-patent infections.

Moreover, in the absence of diagnostic facilities, chemo-preventive strategies such as intermittent preventive treatment for forest goers can be thought of, as being done in Cambodia. ${ }^{36}$ Scale-up of detection of asymptomatic and low-parasitemic patients through active case detection in the high transmission areas using molecular techniques has been included in the U.S. President's Malaria Initiative Thailand, Lao PDR and Regional Malaria Operational Plan FY 2020. ${ }^{37}$ These need to be explored in Indian settings as well.

\section{MALARIA SURVEILLANCE FOR CONTROL AND ELIMINATION}

India's malaria surveillance reporting system in general suffers from a number of limitations, inadequate linkage with private health sector, failure to detect outbreaks and hotspots in time, lack of surveillance of mobile and tribals populations, insufficient interstate monitoring and surveillance within the country and lack of true estimates of at-risk population and more so in forested areas. ${ }^{38}$ Monthly aggregated data reported via paper based systems miss out on crucial and timely information. ${ }^{38}$ Communities living in interior forested areas, migrants and tribal populations are often missed out. ${ }^{38}$ Pregnant womens and children represent high risk groups and need to be captured in the surveillance network and prioritised for timely malaria management. India needs to switch to digital, near real time surveillance via mobile apps and engage with options for timely data transfer and analysis using digital dashboards and data-backed action especially for these forested areas. ${ }^{39}$ Innovative methods and tools are the urgent needs to bolster the healthcare systems of these underserved areas. India can replicate some of the tools used in the global fight against COVID-19 for malaria elimination including enhanced disease surveillance, compliance to disease mitigation strategies, community engagement, inclusion of dynamic dashboard and digital technologies for monitoring and mitigation. ${ }^{40}$ The hard-to-reach forested areas of India will especially benefit from technological tools that obviate the need for human reliance on surveillance.

\section{CONCLUSIONS}

The main challenges facing malaria control in the forested areas include human, ecological, socioeconomic and biological factors of insecticide and drug resistance. Social practices and beliefs of communities living in the forested areas may contribute to their increased vulnerability. Due to the presence of conductive environmental and human factors, forested areas have been hotspots for malaria transmission. The number of deaths from the forested districts is quite high as per their population proportions. Programme interventions for increased community participation for enhancing its understanding of malaria and malaria-related treatments will be important. A decrease in the dependence on UMPs and irrational medicine will inevitably help in malaria control. Increased community participation in vector control and source reduction may lead to longer-term lowering in transmission. The vector behaviour suggests that the current vector control tools are practical but newer tools may be required due to increasing insecticide resistance and changing vector behaviour. At a molecular level, routine detection of low density infections and tracking of drug and resistance are needed immediatly. The success in control of forest malaria will undoubtedly have a significant impact on the overall malaria trajectorires across India. Forest malaria remains a prevailing obstacle for malaria control and it is timely to implement tailormade intervention strategies for its control.

Acknowledgements AS is supported by JC Bose fellowship and with funding from DBT, DST, ICMR, NIH and GHIT. The malaria data were provided by NVBDCP to ICMR-NIMR upon request and we are thankful for the same. Authors are thankful to Dr. Manju Rahi for her suggestions during manuscript revision.

Contributors AS initiated the study and RR collected the data. Both analysed it and both wrote the manuscript.

Funding The authors have not declared a specific grant for this research from any funding agency in the public, commercial or not-for-profit sectors.

Map disclaimer The depiction of boundaries on the map(s) in this article does not imply the expression of any opinion whatsoever on the part of BMJ (or any member of its group) concerning the legal status of any country, territory, jurisdiction or area or of its authorities. The map(s) are provided without any warranty of any kind, either express or implied.

Competing interests None declared.

Patient consent for publication Not required.

Provenance and peer review Not commissioned; externally peer reviewed. 
Data availability statement All the data used in the manuscript is available with authors.

Supplemental material This content has been supplied by the author(s). It has not been vetted by BMJ Publishing Group Limited (BMJ) and may not have been peer-reviewed. Any opinions or recommendations discussed are solely those of the author(s) and are not endorsed by BMJ. BMJ disclaims all liability and responsibility arising from any reliance placed on the content. Where the content includes any translated material, BMJ does not warrant the accuracy and reliability of the translations (including but not limited to local regulations, clinical guidelines, terminology, drug names and drug dosages), and is not responsible for any error and/or omissions arising from translation and adaptation or otherwise.

Open access This is an open access article distributed in accordance with the Creative Commons Attribution Non Commercial (CC BY-NC 4.0) license, which permits others to distribute, remix, adapt, build upon this work non-commercially, and license their derivative works on different terms, provided the original work is properly cited, appropriate credit is given, any changes made indicated, and the use is non-commercial. See: http://creativecommons.org/licenses/by-nc/4.0/.

\section{REFERENCES}

1 WHO. World malaria report 2020: 20 years of global progress and challenges. Geneva: World Health Organization, 2020.

2 NVBDCP. Magnitude of the problem. Available: https://nvbdcp.gov. in/index4.php?lang=1\&level=0\&linkid $=420 \&$ lid $=3699$

3 von Seidlein L, Peto TJ, Tripura R, et al. Novel approaches to control malaria in forested areas of Southeast Asia. Trends Parasitol 2019;35:388-98.

4 Singh N, Mishra AK, Shukla MM, et al. Forest malaria in Chhindwara, Madhya Pradesh, central India: a case study in a tribal community. Am J Trop Med Hyg 2003;68:602-7.

5 India Npo. India at a glance. Available: https://www.india.gov.in/ india-glance/profile

6 Das A, Anvikar AR, Cator LJ, et al. Malaria in India: the center for the study of complex malaria in India. Acta Trop 2012;121:267-73.

7 Schapira A, Boutsika K. Malaria ecotypes and stratification. Adv Parasitol 2012;78:97-167.

8 Orlov VS, Semashko IN, World Health Organization. Malaria Action P. Malaria stratification as a tool in developing the strategy and tactics for modern long-term malaria control programmes / by V. S. Orlov \& I. N. Semashko. Geneva: World Health Organization World Health Organization, 1986.

9 Guerra CA, Snow RW, Hay SI. A global assessment of closed forests, deforestation and malaria risk. Ann Trop Med Parasitol 2006;100:189-204.

10 Canavati SE, Kelly GC, Quintero CE, et al. Risk factor assessment for clinical malaria among forest-goers in a pre-elimination setting in Phu Yen Province, Vietnam. Malar J 2019;18:435.

11 India FSo. State of forest report 2019, 2019.

12 Prothero RM. Malaria, forest and people in Southeast Asia. Singapore Journal of Tropical Geography 2002.

13 Minakawa N, Sonye G, Mogi M, et al. The effects of climatic factors on the distribution and abundance of malaria vectors in Kenya. $J$ Med Entomol 2002;39:833-41.

14 Koenraadt CJM, Githeko AK, Takken W. The effects of rainfall and evapotranspiration on the temporal dynamics of Anopheles gambiae s.s. and Anopheles arabiensis in a Kenyan village. Acta Trop 2004;90:141-53.

15 Aragao MB. [Some microclimatic measurements, in a forest of the "bromeliad-malaria" region, in Santa Catarina, Brazil. III. Conditions of humidity measured with hygrographs]. Rev Bras Med 1960;12:395-414

16 Knowledge RRA. Attitude and practices survey and Entomological situation analysis in malaria endemic tribal villages of Surajpur district, Chhattisgarh, India. J Commun Dis 2019;51:1-5.

17 Singh MP, Chand SK, Saha KB, et al. Unlicensed medical practitioners in tribal dominated rural areas of central India: bottleneck in malaria elimination. Malar J 2020;19:18.
18 Kar NP, Kumar A, Singh OP, et al. A review of malaria transmission dynamics in forest ecosystems. Parasit Vectors 2014;7:265.

19 Nofal SD, Peto TJ, Adhikari B, et al. How can interventions that target forest-goers be tailored to accelerate malaria elimination in the greater Mekong subregion? A systematic review of the qualitative literature. Malar J 2019;18:32.

20 Subbarao SK, Nanda N, Rahi M, et al. Biology and bionomics of malaria vectors in India: existing information and what more needs to be known for strategizing elimination of malaria. Malar $J$ 2019;18:396.

21 Chand G, Chaudhary NK, Soan V, et al. Transmission dynamics \& epidemiology of malaria in two tribal districts in Madhya Pradesh, India. Indian J Med Res 2015;141:556-66.

22 Sharma VP, Dev V. Biology \& control of Anopheles culicifacies Giles 1901. Indian J Med Res 2015;141:525-36.

23 Singh N, Chand SK, Bharti PK, et al. Dynamics of forest malaria transmission in Balaghat district, Madhya Pradesh, India. PLoS One 2013;8:e73730.

24 Pradhan K. Anopheles (Cellia) fluviatilis James 1902: an efficient vector of malaria in hills and foothills of India. In: Dev V, ed. Vector biology and control an update for malaria elimination initiative in India. India: The National Academy of Sciences, India, 2020: 23-32.

25 Dev V, Manguin S. Biology, distribution and control of Anopheles (Cellia) minimus in the context of malaria transmission in northeastern India. Parasit Vectors 2016;9:585.

26 Prakash A, Bhattacharyya DR, Mohapatra PK, et al. Malaria transmission risk by the mosquito Anopheles baimaii (formerly known as an. dirus species D) at different hours of the night in northeast India. Med Vet Entomol 2005;19:423-7.

27 Dutta P, Bhattacharyya DR, Khan SA, et al. Feeding patterns of Anopheles dirus, the major vector of forest malaria in North East India. Southeast Asian J Trop Med Public Health 1996;27:378-81.

28 Bhatt RM, Sharma SN, Barik TK, et al. Status of insecticide resistance in malaria vector, Anopheles culicifacies in Chhattisgarh state, India. J Vector Borne Dis 2012;49:36-8.

29 Kleinschmidt I, Bradley J, Knox TB, et al. Implications of insecticide resistance for malaria vector control with long-lasting insecticidal nets: a WHO-coordinated, prospective, international, observational cohort study. Lancet Infect Dis 2018;18:640-9.

30 Chourasia MK, Raghavendra K, Bhatt RM, et al. Additional burden of asymptomatic and sub-patent malaria infections during low transmission season in forested tribal villages in Chhattisgarh, India. Malar J 2017;16:320.

31 Ranjha R, Dutta GDP, Gitte SV. School-Age children as asymptomatic malaria reservoir in tribal villages of Bastar region, Chhattisgarh. Indian Pediatr 2019;56:873-5.

32 Panda B, Mohapatra MK, Paital S, et al. Prevalence of afebrile malaria and development of risk-scores for gradation of villages: a study from a hot-spot in Odisha. PLoS One 2019;14:e0221223.

33 Ganguly S, Saha P, Guha SK, et al. High prevalence of asymptomatic malaria in a tribal population in eastern India. J Clin Microbiol 2013;51:1439-44.

34 Sumner KM, Freedman E, Abel L, et al. Genotyping cognate Plasmodium falciparum in humans and mosquitoes to estimate onward transmission of asymptomatic infections. Nat Commun 2021;12:909.

35 Okell LC, Bousema T, Griffin JT, et al. Factors determining the occurrence of submicroscopic malaria infections and their relevance for control. Nat Commun 2012;3:1237.

36 Kunkel A, Nguon C, Iv S, et al. Choosing interventions to eliminate forest malaria: preliminary results of two operational research studies inside Cambodian forests. Malar J 2021;20:51.

37 PMI. US. President's Malaria Initiative Thailand, Lao PDR, and Regional Malaria Operational Plan FY 2020, 2020.

38 Rahi M, Das P, Sharma A. Malaria elimination in India requires additional surveillance mechanisms. J Public Health 2021. doi:10.1093/pubmed/fdab106. [Epub ahead of print: 05 Apr 2021].

39 Rahi M, Sharma A. For malaria elimination India needs a platform for data integration. BMJ Glob Health 2020;5:e004198.

40 Rahi M, Das P, Sharma A. COVID-19 mitigation steps provide a blueprint for malaria control and elimination. Am J Trop Med Hyg 2020;103:28-30. 